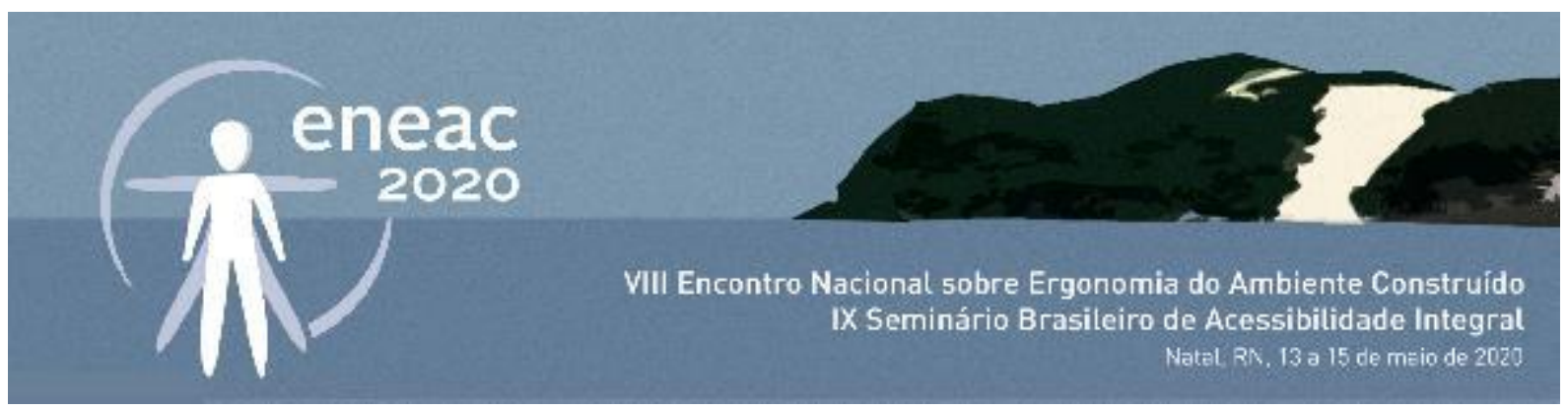

\title{
A cor como ferramenta identitária para sinalização acessível: o estudo de caso da reitoria da UFPB.
}

\author{
The color as an identifying tool for accessible signage: the study \\ case of the UFPB's rectory
}

\author{
ABRAÃO PINTO DE OLVIERA NÓBREGA \\ Graduação, Universidade Federal da Paraíba, abraaonobrega02@gmail.com
}

MARCELO ANDRADE DINIZ

Mestrado, Universidade Federal da Paraíba, marceloadiniz@gmail.com

\section{RESUMO}

Tornar um ambiente acessível vai além de possibilitar o livre deslocamento e equidade em respeito aos acessos. Engloba questões muitas vezes subjugadas e tidas como secundárias, dentre elas, a orientabilidade, compreensão e/ou legibilidade espacial. Este artigo apresenta os estudos desenvolvidos para a iniciativa de extensão "Projeto participativo de sinalização para a reitoria da UFPB: agregando acessibilidade ao ambiente construído, ano 2 ", enfatizando uma das suas vertentes projetuais aplicadas: o uso da cor como ferramenta identitária para sinalização. O objetivo da pesquisa entende-se por desenvolver um projeto de sinalização acessível que integrasse diferentes modelos e tipologias de informação. Assim, possibilitando variabilidade em arranjos funcionais para melhora da orientabilidade no interior da reitoria da Universidade Federal da Paraíba. A abordagem técnicometodológica é fundamentada pela discussão trazida por conceitos como: desenho universal, percepção espacial e orientabilidade autônoma. Há também a uma forte relação com o planejamento estratégico através de lógicas da decomposição ambiental inerentes ao wayfinding. Neste cenário, os processos de compartimentação funcional e discussão sobre graus de interação pelas atividades e proximidade física serviram para sua setorização de modo otimizado. Deste modo, os elementos de sinalização desenvolvidos puderam ser condensados, gerando um produto mais coerente e integrado nas suas variações - por existir informações táteis e visuais dispersas nos planos verticais e horizontais. Uma das soluções desenvolvidas em consequência aos estudos é a definição e adoção do conceito imagético utilizado, caracterizado pelo uso de uma escala cromática determinante para a identidade visual do projeto, também vinculada aos outros modelos propostos.

PALAVRAS-CHAVE: Cores, orientabilidade, identidade visual, wayfinding, sinalização acessível.

\section{ABSTRACT}

Making an environment accessible goes beyond allowing free movement and fairness about the access. 




It encompasses issues often subjugated and taken as secondary, among them, the orientability, comprehension and/or spatial readability. This article presents the studies developed for the extension initiative "Participatory signaling project for the UFPB's rectory: adding accessibility to the built environment, year 2", emphasizing one of its applied design aspects: the use of color as an identity tool for signaling. The objective of the research is to develop an accessible signaling project that integrates different models and typologies of information. Thus, allowing variability in functional arrangements to improve orientability within the rectory of Paraiba's Federal University. The technical-methodological approach is based on the discussion brought by concepts such as universal design, spatial perception, and autonomous orientability. Also, there is a strong relationship with strategic planning through the logic of environmental decomposition inherent in wayfinding. In this scenario, the processes of functional compartmentalization and discussion about the degrees of interaction by activities and physical proximity served to optimize their sectorization. Thus, the developed signaling elements could be condensed, generating a more coherent and integrated product in its variations - because there is tactile and visual information dispersed in the vertical and horizontal planes. One of the solutions developed as a result of the studies is the definition and adoption of the imagetic concept used, characterized by the use of a chromatic scale that determines the visual identity of the project, also linked to the other proposed models.

KEYWORDS: Colors, orientability, visual identity, wayfinding, accessible signage.

\section{INTRODUÇÃO}

Possibilitar o trânsito seguro e autônomo não é a única preocupação ao se projetar um ambiente acessível. Existem diversas nuances e demandas que, muitas vezes, são sobrepostas e induzidas como secundárias, sendo descritas apenas como consequência dos públicos e suas diferentes características fisiológicas. Dischinger et. al. (2008) abordam que proporcionar ao usuário a compreensão e usabilidade do ambiente em questão, quer seja urbano ou arquitetônico, Ihe gerando autonomia para decisões de locomoção e orientação, também auxiliados pelo rompimento de barreiras físicas, é o que torna essa espacialidade realmente acessível.

Nesse cenário, vale salientar o panorama jurídico e normativo existente na atual conjuntura políticosocial brasileira. É através de determinações como a lei número 13.146 (BRASIL, 2015) popularmente conhecida como estatuto da pessoa com deficiência - que as mudanças e melhorias são abordadas. Esta existe como ferramenta para exigências mínimas sobre condições justas em acessibilidade. Visto que apresenta características e padrões necessários para o ambiente urbano e arquitetônico, visando proporcionar equidade em respeito ao público com deficiência. Assim, é muitas vezes vinculada com a NBR 9050 (ABNT, 2015), pelo seu viés técnico, com todas as suas sugestões e determinações para modificações no ambiente construído.

Ao direcionar a análise para o meio educacional há também o decreto de lei número 5.296 (BRASIL, 2004), focado nas instituições de ensino, considerando todos os seus níveis. Nele há a determinação que os ambientes educacionais sejam adequados ao público com deficiência. Para isso podem manifestar suas adaptações através de intervenções no ambiente já consolidado ou na construção de novos espaços e/ou alternativas. Contudo, por mais que as determinações existam, há, em contrapartida, uma série de problemáticas ao avaliar o cenário de instituições de ensino superior. 


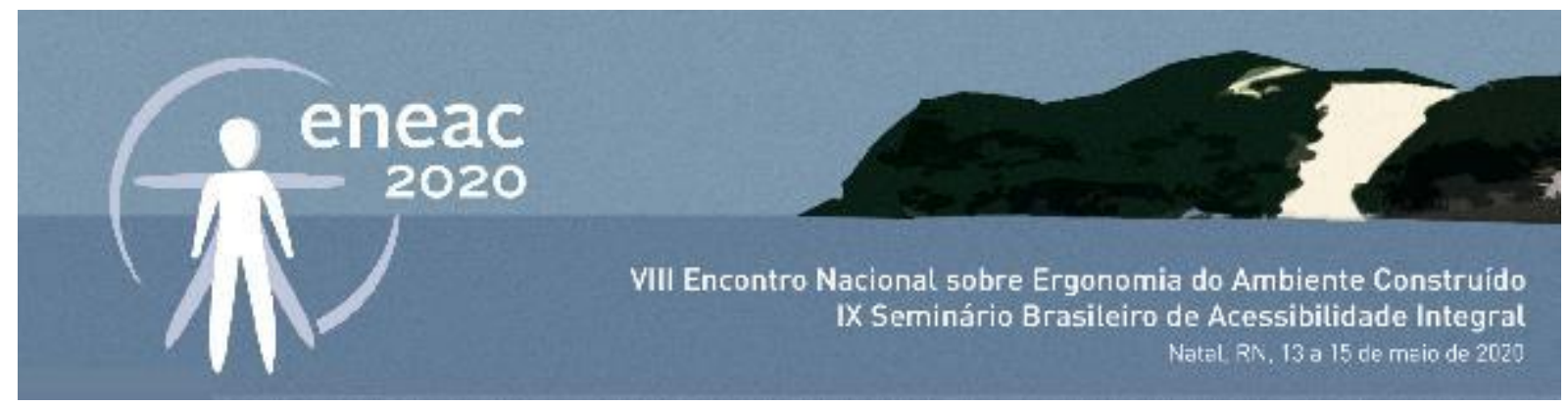

Boa parte dos campi universitários consolidados é anterior ao entendimento da importância da acessibilidade como característica intrínseca na produção projetual. Deste modo, ambientes urbanos e arquitetônicos são fortemente vinculados a definições de público muitas vezes excludentes. É necessária a discussão acerca da produção pensada para o homem médio (IIDA, 2016), que, com suas dimensões antropométricas perfeitas, seria a base mais coerente para desenvolvimento de objetos, mobiliários e até mesmo dimensionamento arquitetônico.

Todavia, suas características fisionômicas fogem ao dinamismo característico brasileiro, principalmente por serem voltadas ao padrão eurocêntrico. Além disso, o homem médio desconsidera algumas variações físicas e busca atender a um percentual específico, fato que tende a dificultar adaptações ao cenário humano real. Deste modo, não apenas pessoas com deficiência são excluídas, mas também, usuários caracterizados por padrões em extremos físicos, destacando questões como altura, peso e outras.

No Campus I da Universidade Federal da Paraíba (UFPB) (Figura 1) a situação não é diferente e iniciativas como esta se mostram necessárias. A escolha da reitoria vem da sua importância para o funcionamento da instituição, sendo uma edificação emblemática para o projeto piloto. Dada a complexidade funcional e mudanças arquitetônicas desenvolvidas ao longo dos anos, a reitoria se assemelha muitas vezes a um labirinto. Além da dificuldade de sua legibilidade espacial, há a falta de elementos de sinalização eficazes - seja pela pouca quantidade e/ou falta de informações coerentes e acessíveis - tornando o processo de orientação uma difícil missão para toda a comunidade.
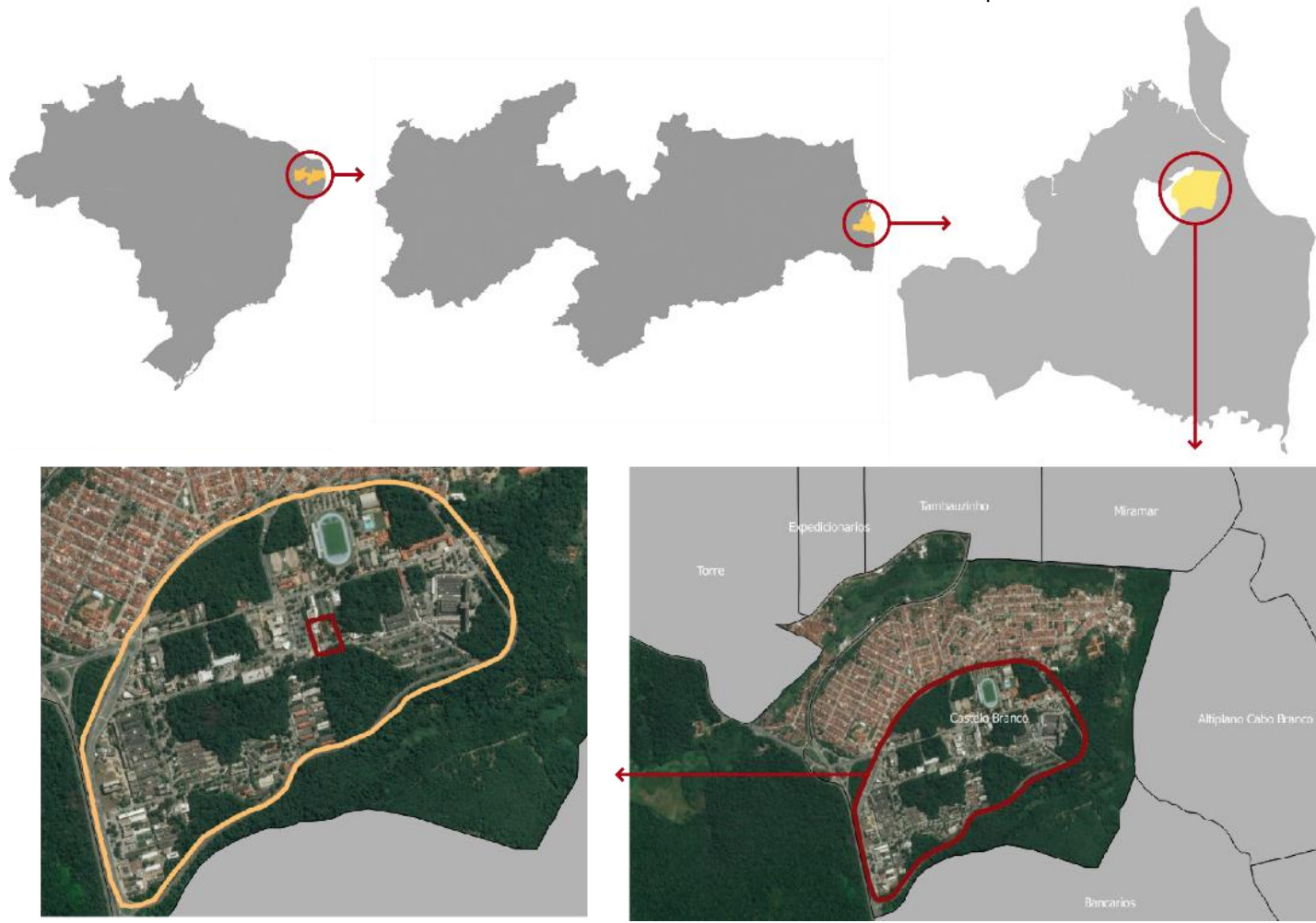

Fonte: Adaptado de Google Earth, 2020. 


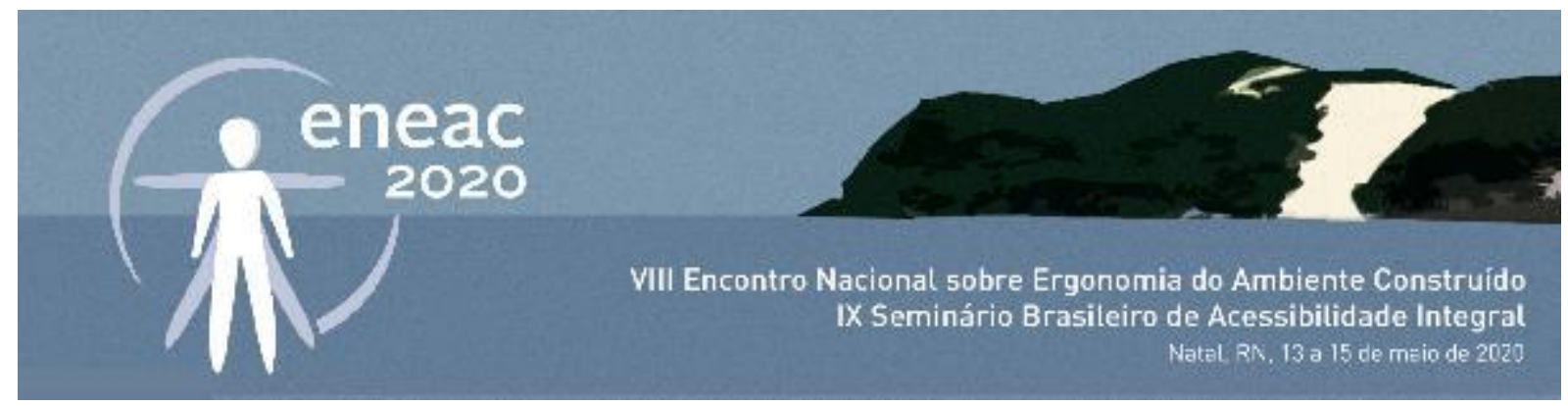

\section{Objetivos}

Dentro de sua abordagem a pesquisa objetivava primordialmente desenvolver um projeto de sinalização acessível que integrasse diferentes modelos e tipologias de informação, permitindo melhora da orientabilidade interna e variação de arranjos funcionais para a reitoria da Universidade Federal da Paraíba, Campus I. E, de modo específico:

- Atender as diferentes demandas dos usuários com deficiência (UCD) e sem deficiência (USD);

- Desenvolver sistemas de sinalização específicos e independentes que podem ser vinculados e funcionarem em conjunto através da identidade visual total.

- Entender a dinâmica e funcionamento das cores como elemento de integração visual para os diferentes componentes.

\section{ABORDAGEM TEÓRICO-METODOLÓGICA}

Para atender seus objetivos a presente pesquisa passou por três momentos específicos estruturantes. O primeiro caracteriza-se pela revisão bibliográfica e reconhecimento do objeto de estudo. Nessa etapa do trabalho foram buscadas as diferentes linhas de pesquisa que pudessem embasar os objetivos da intervenção, resultando assim nos conceitos a serem abordados e desenvolvidos.

$O$ desenho universal veio como a principal ferramenta inclusiva por ser uma vertente que permeia diversos campos do conhecimento voltados ao desenvolvimento de produtos, espaços e/ou equipamentos. Trata de questões ergonômicas, físicas e qualitativas sobre os produtos de áreas como design e arquitetura, entre outras (DUARTE; COHEN, 2014). Assim, os ideais pregados iam de acordo com o input da pesquisa, uma vez que esta buscava produzir elementos que pudessem atender a todos os públicos, possibilitando diferentes sistemas e arranjos funcionais de acordo com as demandas e particularidades dos usuários e do pavimento em questão.

O segundo eixo é caracterizado pela orientabilidade autônoma, fortemente vinculada ao wayfinding. Esse pilar surge em consequência da complexidade da organização espacial da edificação, como pode-se observar na planta baixa do térreo, na figura 2 . A reitoria do campus I detém um programa de necessidades vasto e bastante conectado entre si, com definição de rotas específicas, porém, pela grande subdivisão de funções, acaba por se tornar um labirinto. Assim, fez-se necessário investir um pouco mais de cuidado no estudo da lógica de planejamento. Uma vez que, esta visa proporcionar ao usuário o livre entendimento da ambientação espacial, podendo ser veiculada através de simbologias - iconografia -, lógicas estruturares - sistemas de cores e outros. Assim, é proporcionada identidade visual e maior legibilidade espacial para o usuário (SIMÕES, 2017).

Por fim, vinculado à orientabilidade autônoma, o uso das cores é a principal ferramenta aplicada. Sua percepção pode ser tida como questão secundária em muitos vieses projetuais, porém, no cenário deste trabalho, foi fundamental seu uso e seu estudo. Azevedo, Santos e Oliveira (2000) discutem sobre a importância da cor no ambiente de trabalho, partindo não apenas como elementos de destaque para segurança - por enfatizarem zonas de risco e afins -, mas também por auxiliarem na ordenação e orientação organizacional, principal foco desse projeto. 

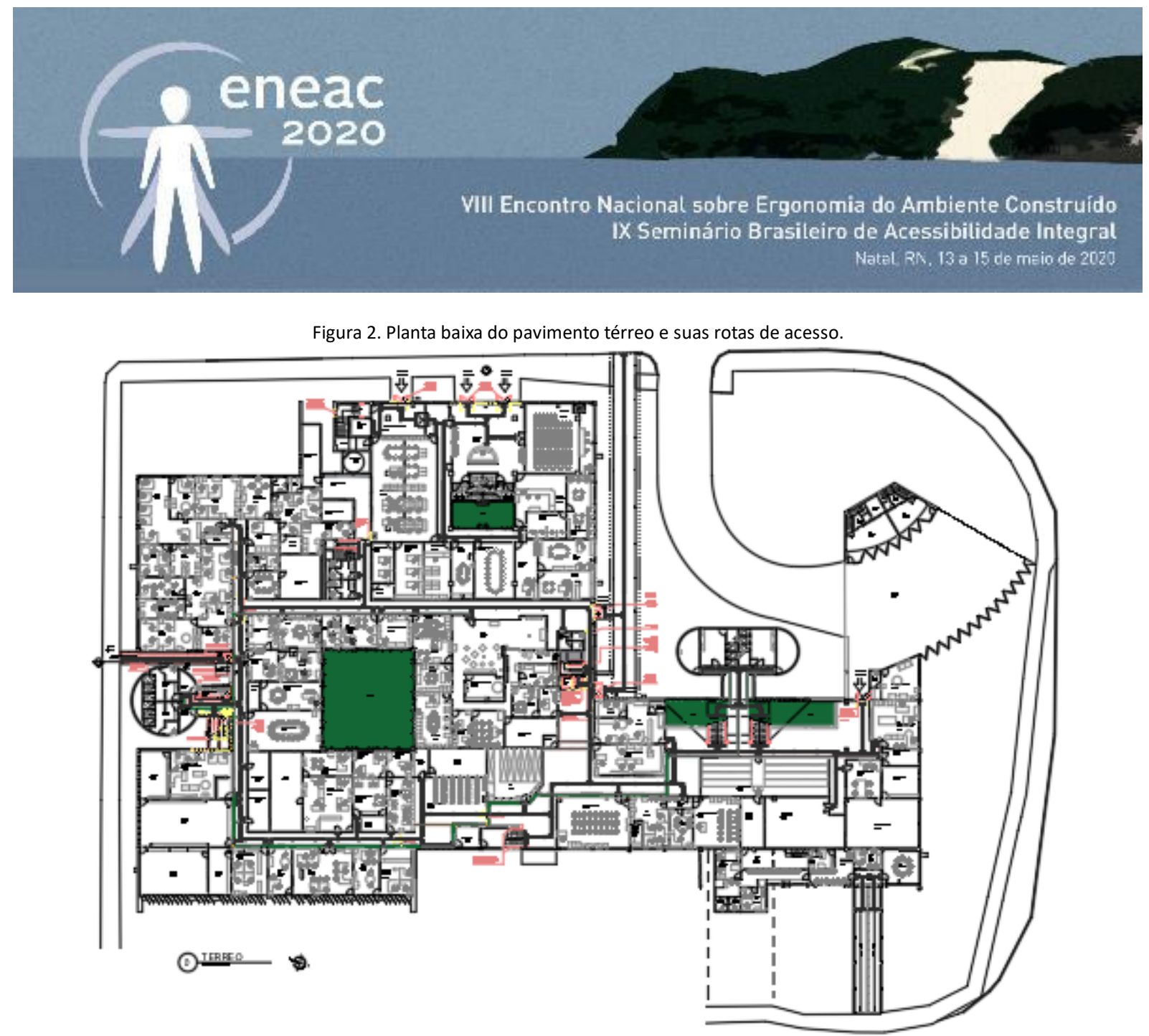

Fonte: Autores, 2020.

Em paralelo a revisão bibliográfica foram realizadas visitações in loco ao objeto de estudo. Estas visavam entender as condições físicas atuais, compreender as rotas mais utilizadas e apreender o a dinâmica de uso, em uma macroescala, para viabilizar as definições futuras. Como sequência das atividades ditas acima análises estruturantes e busca de projetos correlatos foram realizadas.

No momento intermediário, os estudos sobre as dinâmicas com a aplicação de matrizes de relação foram desenvolvidos, também sendo realizada a decomposição da edificação em grupos de trabalho focais. Partindo para ensaios de como poderiam ser os arranjos funcionais dos primeiros protótipos gerados para a sinalização de piso e parede. Em paralelo houve a pesquisa de projetos excetuados tanto em cenário nacional quanto internacional que tivessem a mesma ideologia visual ou inclusiva.

O último momento de seu método é caracterizado pela produção sistêmica. Com todos os diagnósticos e estudos prévios realizados a etapa final foi condensada à produção e consolidação do partido arquitetônico e todos os componentes de sinalização, distribuídos em suas subdivisões de acordo com superfícies de implantação e tipologia de informação.

\section{DEFINIÇÕES PROJETUAIS}

\section{Setorização}

Buscando melhorar a qualidade da legibilidade espacial no objeto de estudo, considerando a aplicação algumas das estratégias de compartimentação espacial discutidas nos subtemas do wayfinding, surgiu a demanda pela redução da complexidade do partido arquitetônico. Esta 


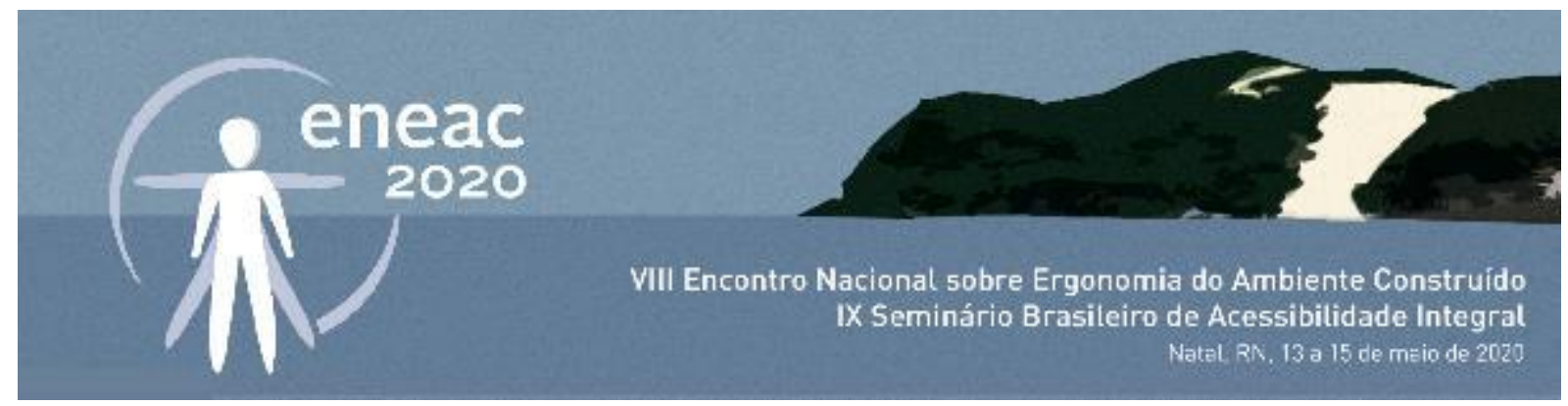

compactação surgiu como mecanismo base para redução das possibilidades de escolha, de modo a otimizar as rotas acessíveis - devidamente sinalizadas com o projeto - facilitando o processo do trânsito interno ao visitante.

Para obter a devida organização, se fez necessária a divisão das atividades em grupos maiores, setorizando o objeto de estudo. Este processo não veio a ser possível em separação por pavimentos, uma vez que há certa rotatividade no funcionamento os ambientes. Assim, os setores estruturados foram organizados de modo a se adaptarem e existirem ou não em todos os pavimentos. Além disso, a funcionalidade dos ambientes é distribuída, abrangendo a edificação de acordo com a disponibilidade espacial possível.

A delimitação espacial, deste modo, foi pensada a partir das funcionalidades atuais, agrupando-as por afinidades e, quando possível, por proximidade física. Resultando na compartimentação lógica da edificação e em um sistema de sinalização condensado, direto e com menores índices de ambiguidade. Essa redução dá-se pelo fato de evitar bifurcações nos caminhos sempre que possível.

Uma amostragem do mapeamento das relações é especializada por intermédio da Figura 3. Sua aplicação dá-se através dos principais ambientes - aqueles com maior intensidade nos fluxos diários. A partir das definições destas ambientações, foram criadas duas matrizes, nelas são destacadas os diferentes graus de interação presentes na edificação. Além disso, evidencia como se dão as relações entre grupos de trabalho, levantando o questionamento sobre suas especializações com base da similaridade de funções e proximidade física propriamente dita.

Figura 3. Matriz das relações, de amostragem, entre salas com maior intensidade de fluxo no primeiro pavimento. Acima com base no grau de vínculo por funções. Abaixo matriz por proximidade física.

\begin{tabular}{|c|c|c|c|c|c|c|c|c|c|c|c|}
\hline Relaçōes Funcionais Primeiro Pav. & Gabinete & PROGEP & CIA & COAPE & PRAPE & CEPACE & NTGI & Comitê Ėtica & Ouvidoria & SODS & Auditório \\
\hline Hall & & & & & & & & & & & \\
\hline Auditório & & & & & & & & & & & \\
\hline SODS & & & & & & & & & & & \\
\hline Comitê de Ética & & & & & & & & & & & \\
\hline NTGI & & & & & & & & & & & \\
\hline COAPE & & & & & & & & & & & \\
\hline Comitê de Inclusão e Acessibilidade & & & & & & & & & & & \\
\hline PROGEP & & & & & & & & & & & \\
\hline Gabinete Reitora & & & & & & & & & & & \\
\hline
\end{tabular}

\begin{tabular}{|c|c|c|c|c|c|c|c|c|c|c|c|}
\hline Relaçōes Espaciais Primeiro Pav. & Gabinete & PROGEP & CIA & COAPE & PRAPE & CEPACE & NTGl & Comitê Ética & Ouvidoria & SODS & Auditório \\
\hline Hall & & & & & & & & & & & \\
\hline Auditório & & & & & & & & & & & \\
\hline$\overline{\text { SODS }}$ & & & & & & & & & & & \\
\hline Ouvidoria & & & & & & & & & & & \\
\hline Comitê de Ėtica & & & & & & & & & & & \\
\hline NTGI & & & & & & & & & & & \\
\hline CEPACE & & & & & & & & & & & \\
\hline PRAPE & & & & & & & & & & & \\
\hline COAPE & & & & & & & & & & \multirow{4}{*}{\multicolumn{2}{|c|}{$\begin{array}{l}\text { Relação Forte } \\
\text { Relaçāo Média } \\
\text { Relação Fraca } \\
\text { Sem Relação }\end{array}$}} \\
\hline Comitê de Inclusão e Acessibilidade & & & & & & & & & & & \\
\hline PROGEP & & & & & & & & & & & \\
\hline Gabinete Reitora & & & & & & & & & & & \\
\hline
\end{tabular}




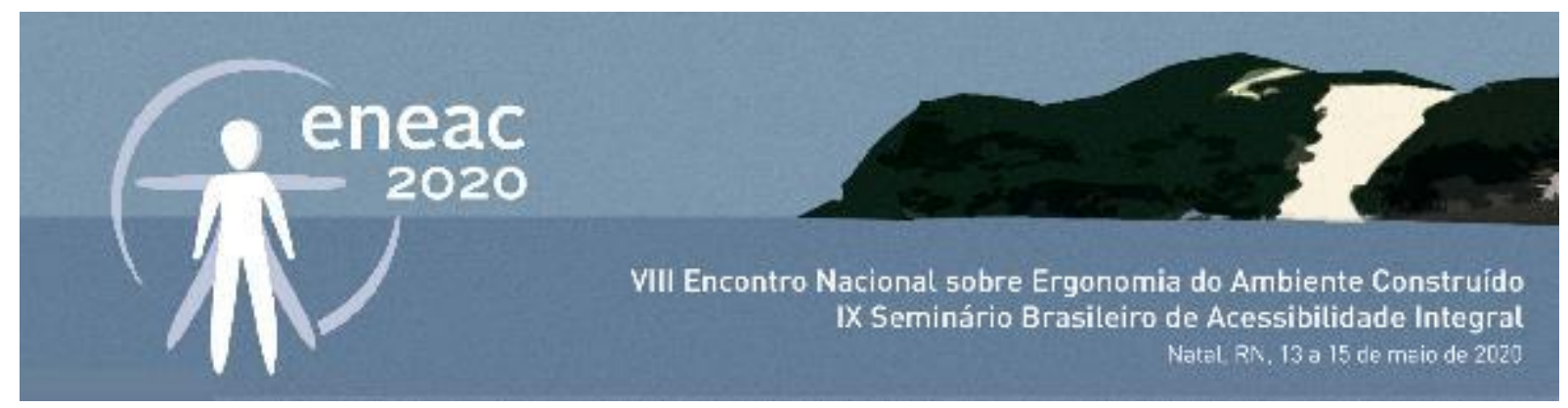

Com a aplicação das matrizes de relações nos demais pavimentos, foi estruturada a lógica de funcionamento da edificação, organizada e segmentada diferentemente em cada andar. Assim, possibilitando o apontamento dos grupos que se interligavam e seu funcionamento. Deste modo, os sete setores abaixo surgiram para simplificação funcional de todas as atividades prestadas à comunidade acadêmica, considerando não apenas discentes e docentes, mas também visitantes e servidores. Estes são:

- Reitorias, representadas pela cor vermelha, são definidas pelos espaços de uso primário do (a) reitor (a), como o gabinete e afins, além das salas diretamente abaixo em hierarquia, possuindo maior vínculo/dependência, como as Comissões da Instituição;

- Pró-reitorias, representadas pela cor laranja, são caracterizadas por todos os ambientes relacionados a quaisquer pró-reitorias e suas componentes. Assim são englobadas salas de reunião, de espera e atendimento, copas e banheiros exclusivos, distinguindo-os dos ambientes de uso geral na edificação;

- Secretarias, representadas pela cor amarela, são definidas pelos ambientes de ouvidoria e apoio à Instituição, também englobando as salas vinculadas e de uso privativo;

- Diretorias, representadas pela cor azul, caracterizadas pelos diretórios e salas relacionadas, além de órgãos de fiscalização externos/independentes;

- Multimídia, referenciadas em marrom, sendo os ambientes de reunião, auditórios, arquivos e semelhantes, porém de uso comum a todos os demais setores da instituição;

- Apoio visitantes, representados em verde, são os ambientes gerais e de livre acesso a qualquer usuário, partindo de recepções, halls e banheiros, a jardins, terraços e semelhantes.

- Apoio funcionários, representado em roxo, são as copas gerais, banheiros e outros ambientes restritos aos servidores, porém não sendo específicos a um público;

\section{Determinação do uso das cores}

Após a criação dos setores o estudo de cores e icnografia veio em sequência. Estes foram utilizados como mecanismos para geração da identidade visual, sendo diretamente influenciados pelo grau de acesso e restrição ao usuário comum. Assim, partiram de símbolos com maior número de arestas a formas mais simplificadas em relação à icnografia. Já na escala cromática foram desenvolvidas com agrupamentos de cores quentes, frias e neutras.

O grupo das cores quentes utilizadas (vermelho, amarelo e laranja) foram vinculadas aos ambientes de maior especificidade de função e com menor acesso/fluxo por parte de usuários comum visitantes. Esta definição legitima-se uma vez que são desempenhadas atividades com maiores graus de responsabilidade e que tendem a ser vinculadas diretamente ao funcionamento interno da instituição, bem como de cuidado para com a comunidade acadêmica - englobando discentes e docentes.

Em contrapartida as cores frias (verde, roxo e azul) são vinculadas aos ambientes de maior fluxo por parte dos usuários comuns, sendo destinados também a menores índices de especificidade funcional. Uma vez que, com exceção das diretorias - representadas em azul - os ambientes das cores frias são 




de uso comum a seus públicos alvos, um para servidores da instituição e outro para os visitantes, discentes e docentes. Por fim, o setor com cor neutra (marrom) é vinculado também às ambientações mais gerais e de maior fluxo geral, uma vez que abrange todos os auditórios, salas de reunião e arquivos gerais para a instituição.

\section{SISTEMAS DE SINALIZAÇÃO}

\section{Sinalização de parede}

Com a definição das cores a serem trabalhadas e de como estas representariam os respectivos setores - vinculadas na possibilidade de acesso e intensidade de fluxo -, o projeto seguiu para a proposição dos elementos de sinalização a serem aplicados. Dentro do universo de materiais produzidos existiu a divisão dos produtos em grupos, tendo como referência sua superfície de implantação - pisos, paredes e teto - como também, o tipo de veiculação da informação - visual ou tátil. Aqui serão apresentados apenas os elementos que possuem vinculação com cores. Deste modo, as placas específicas de setores, vinculadas diretamente aos ambientes de destino, como pode-se observar na figura 4, além das faixas direcionais coloridas dispostas nos pisos em paralelo com a paginação de pisos táteis.

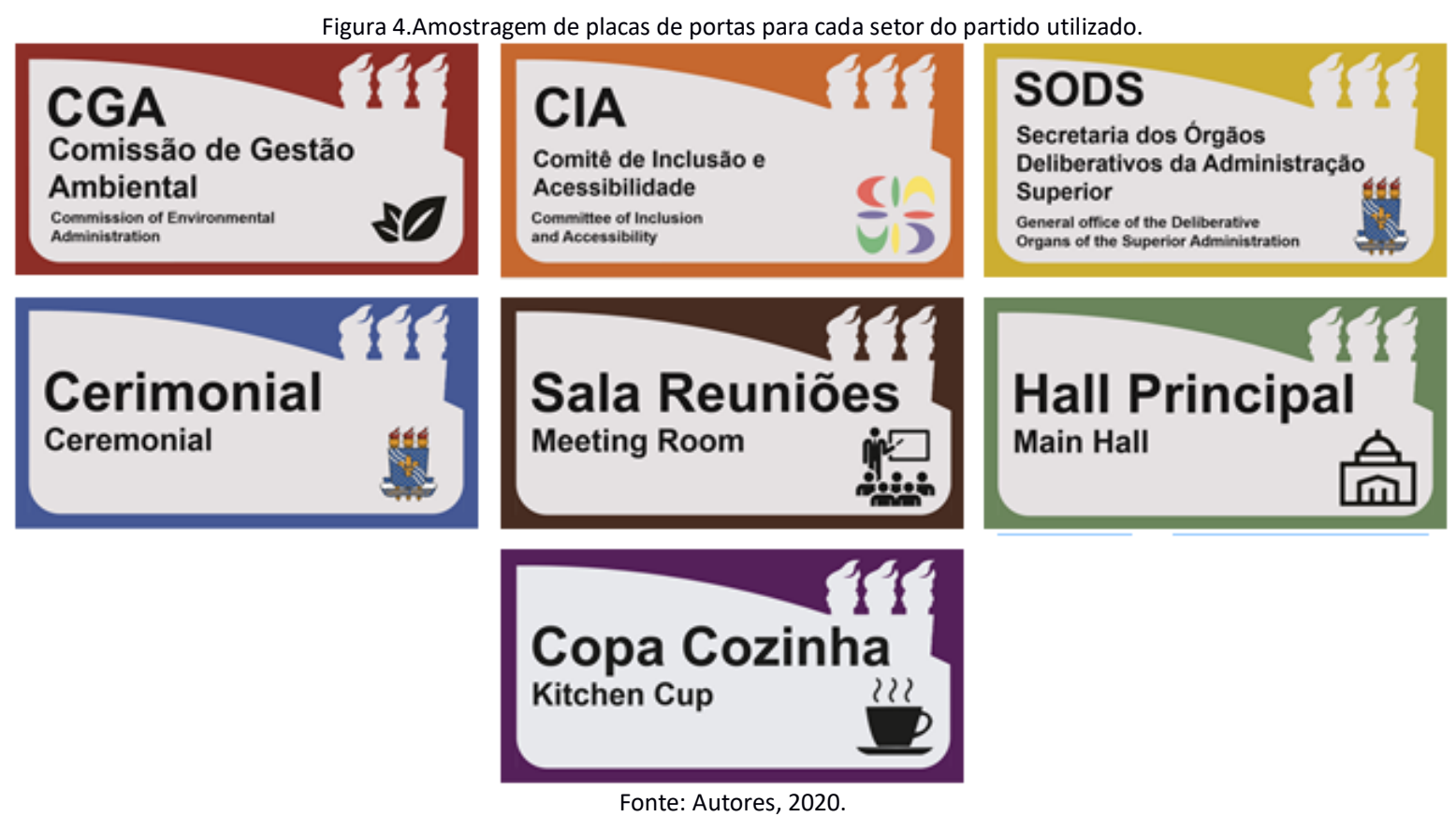

Sua disposição quanto à apresentação de informação é dada em dois cenários, como pode-se observar na figura 5. Em ambas as possibilidades de implantação há presença de informação visual e tátil, diferenciando-se apenas pela demanda de mudança de fluxo para leitura. À esquerda há a placa 


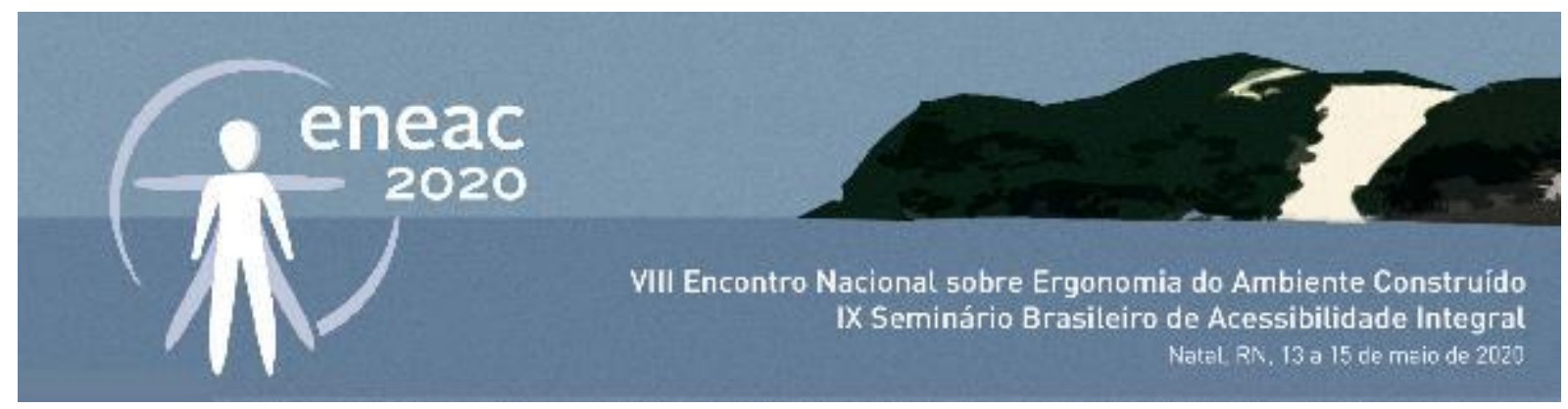

aplicada diretamente nas portas, variando suas bordas externas de acordo com o setor apresentado como fica evidente pelos exemplos trazidos na figura 4 - onde há apenas a identificação do ambiente de modo visual através de texto e simbologia icnográfica.

Além disso, por ser colada à porta é necessária a mudança de fluxo - tendo como referência o trânsito no corredor - para conferir a informação. Já à direita há a placa que segue os mesmos princípios, todavia sua implantação é sacada em relação à porta, apresentando assim a informação diretamente ao fluxo do corredor, possibilitando a leitura e identificação do ambiente destino antes de chegar a ele propriamente.

Figura 5. Modo de implantação das placas específicas. 5.1. Desenho em vista da placa de porta com informação visual e placa braile com informações táteis. 5.2. Corte da placa de porta com saque para o corredor tendo informações visuais.

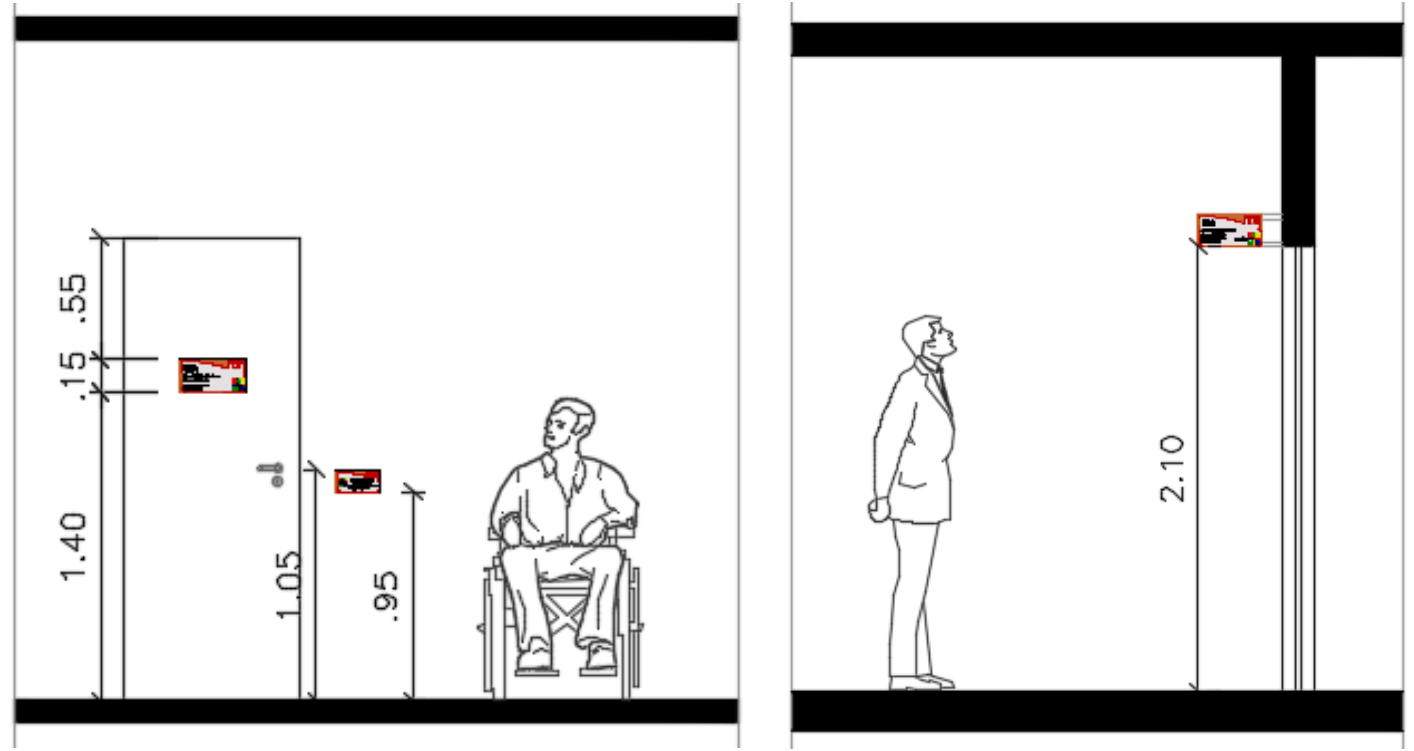

Fonte: Autores, 2020.

As placas em braile são vinculadas em ambas as situações acima, sendo um complemento baseado no ideal de igualdade do desenho universal. Uma vez que, por questões do dimensionamento e disposição da implantação das placas, elas se tornariam inviáveis para a informação tátil e sua leitura. Deste modo, não sendo possível o uso diverso em apenas um produto, a solução alternativa e fisicamente próxima foi aplicada para manter o viés inclusivo do projeto. Assim, estas placas também possuem as características imagéticas da identidade geral do conjunto, diferenciando-se pela possibilidade do toque.

Essa lógica também é utilizada nas placas com informações gerais do pavimento (Figura 6). Nelas há a apresentação da simbologia tátil para os setores, com veiculação das cores e simbologia adotada, existindo também um mapa tátil simplificado do andar. Este elemento é o elo de ligação entre as faixas direcionais coloridas e os demais elementos de sinalização, visto que elas são os marcos iniciais de onde todas as faixas partem para a distribuição pelo andar. 

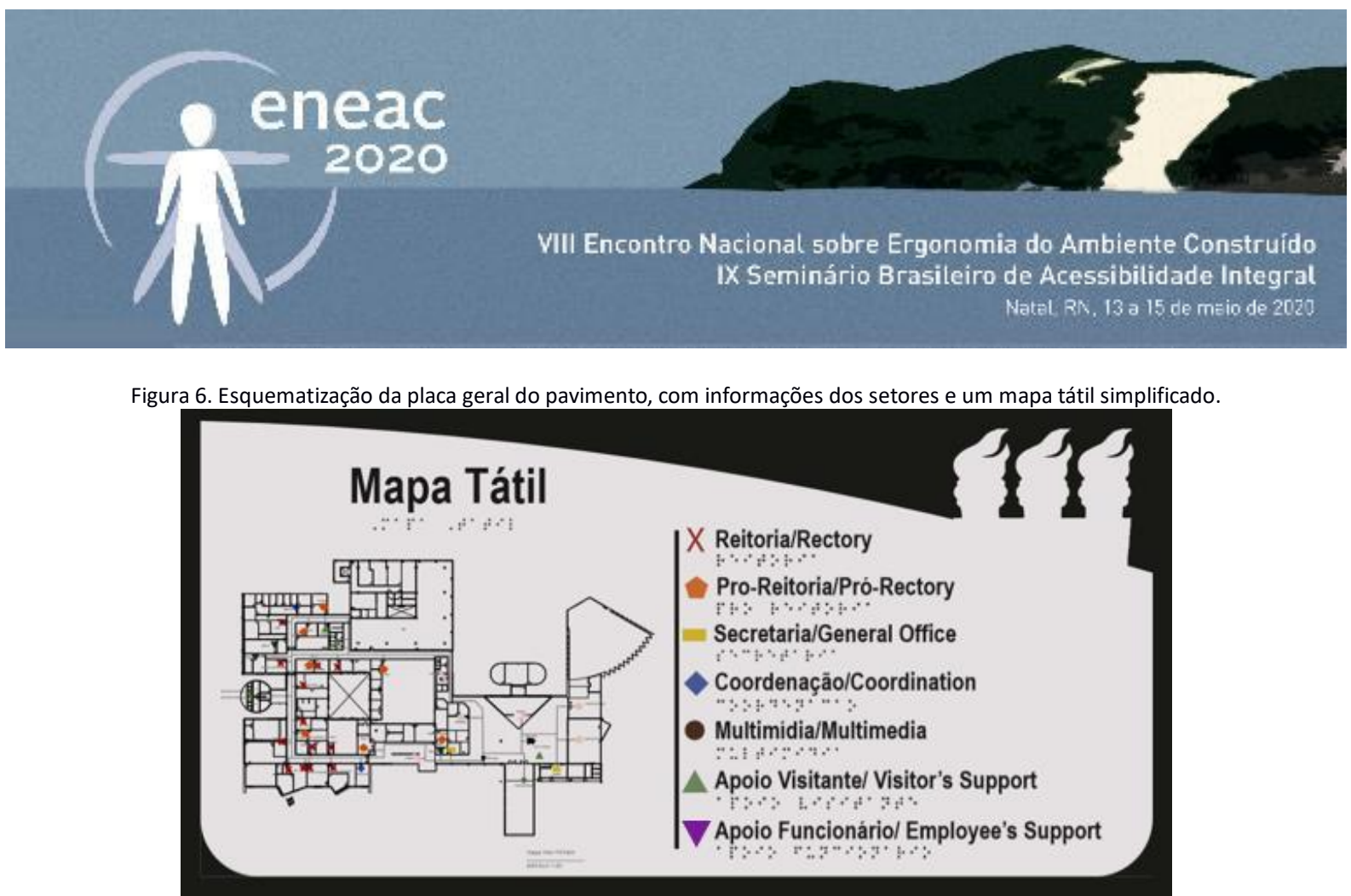

Fonte: Autores, 2020.

\section{Sinalização de piso}

O outro componente projetual vinculado ao uso de cores dá-se nas faixas direcionais. Elas são definidas a partir de um marco zero em cada pavimento, este sempre é nas imediações do acesso principal ao pavimento em questão. Deste modo, no térreo as faixas se distribuem a partir da entrada com maior fluxo, enquanto nos demais pisos é vinculada às imediações das circulações verticais. No primeiro pavimento (Figura 7) é um caso particular, visto que, pela implantação da edificação sob a qualidade topográfica, tanto o primeiro andar quanto o térreo possuem acessos diretos pelas calçadas de entorno da edificação.

A distribuição das faixas direcionais segue baseada na presença dos setores em cada pavimento, como já abordado anteriormente, não existindo em nenhum dos andares há a presença dos sete. Deste modo, há diferentes quantidades de faixas em cada andar, relacionadas à demanda existente. Ao se distanciarem do marco zero elas se distribuem no pavimento - sendo aplicadas em paralelo aos pisos táteis - direcionando o visitante até as salas, parando diante dos acessos aos ambientes.

Figura 7. Trecho do primeiro andar do marco inicial da distribuição de faixas coloridas pelo piso e sua relação com paginação de pisos táteis.

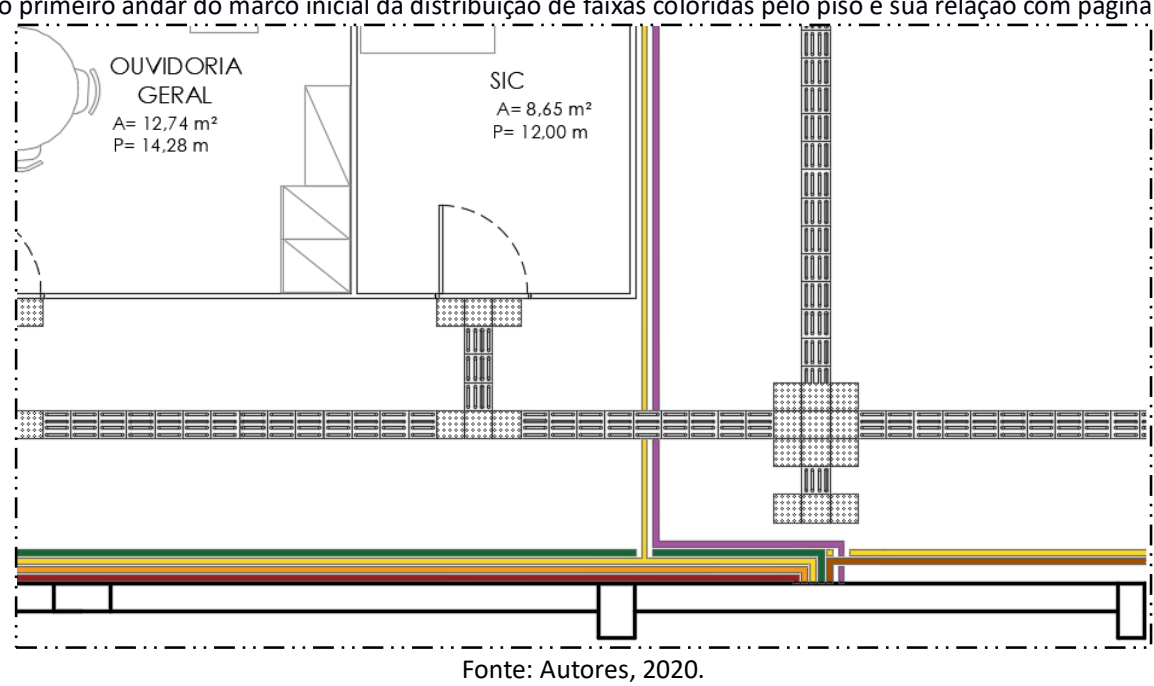




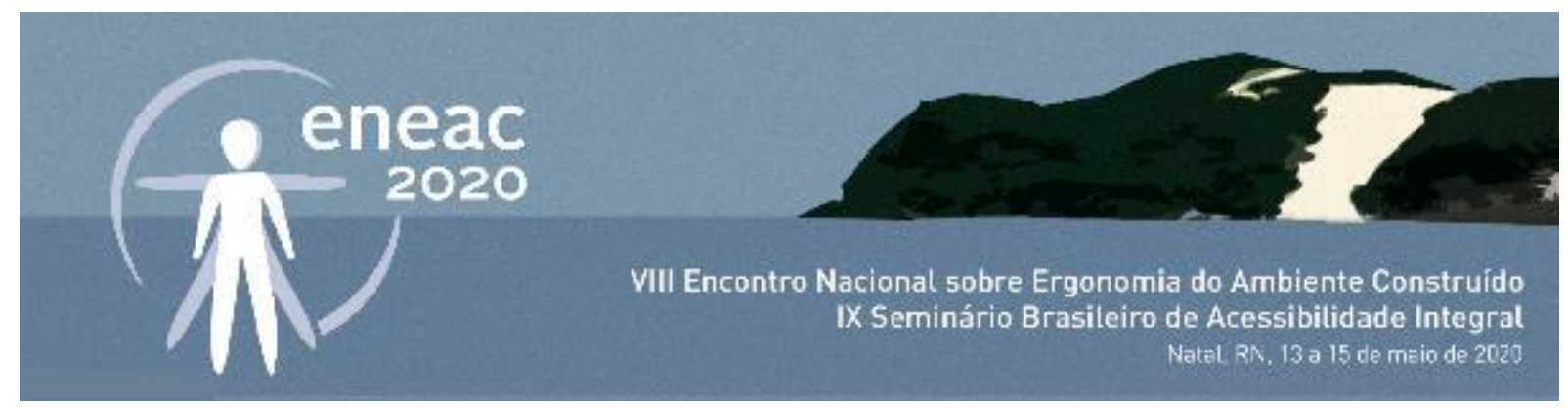

Outra característica importante é o posicionamento quanto a distribuição das faixas. Estas sempre seguem vinculadas à esquerda dos corredores, assim, além da integração visual da informação temse também a constância do acesso a esta, proporcionando maior segurança ao usuário. Assim a paginação desenvolvida nos pisos segue uma lógica contínua com as faixas ao lado e os pisos táteis centralizados, havendo as mudanças de fluxo de acordo com à necessidade (Figura 8).

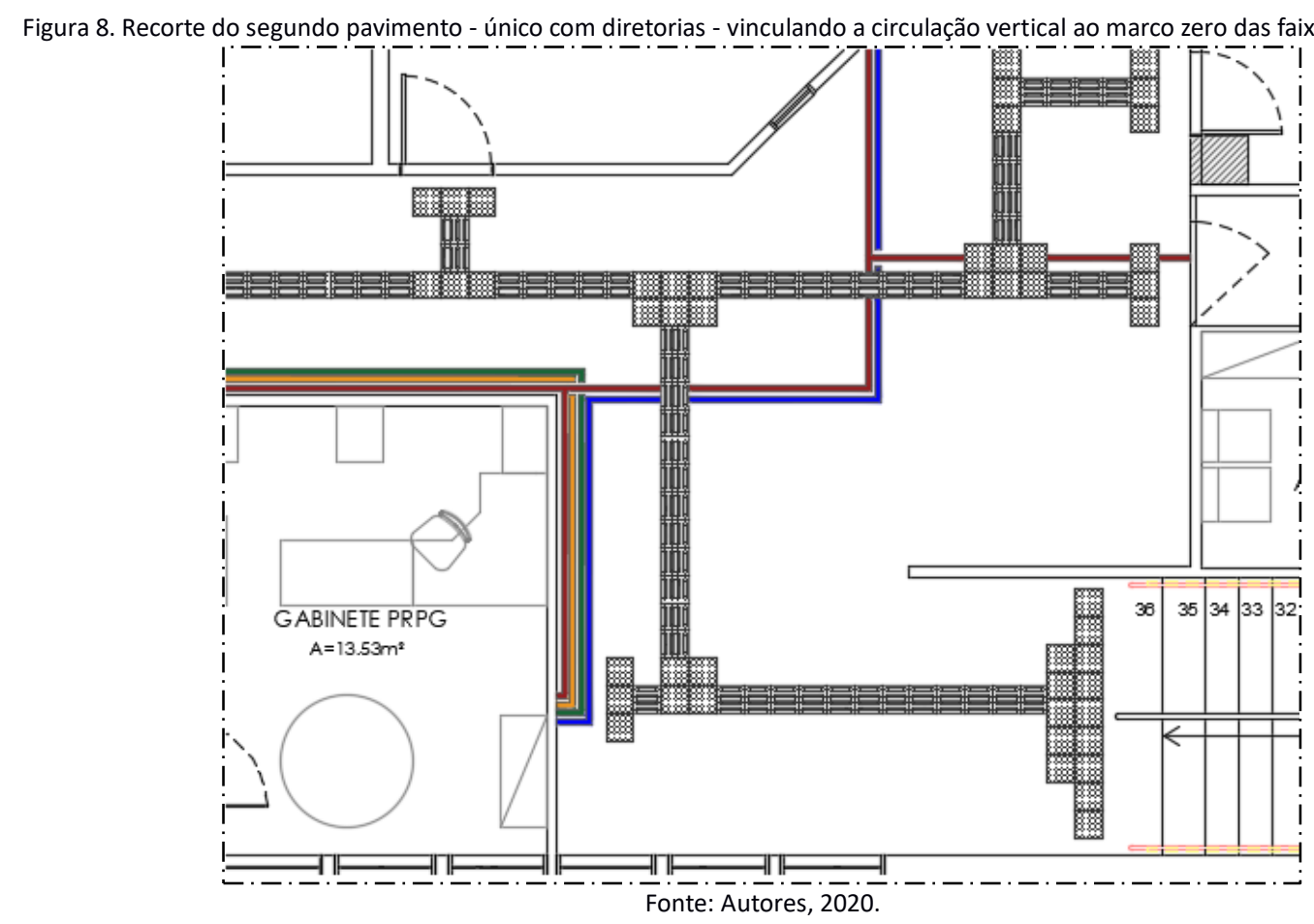

\section{CONSIDERAÇÕES FINAIS}

Dentro do que se propôs, a iniciativa de extensão conseguiu atingir seus objetivos. Uma vez que teve contato com diferentes sistemas de sinalização que poderiam ser aplicados integrados ou não. Assim viabilizou diversidade para os arranjos funcionais e implantação destes modelos. Foi através das etapas prévias de diagnóstico que o entendimento de funcionamento da edificação foi possível. Nas etapas iniciais foram integrados diferentes grupos de usuários, abordando tanto pessoas com deficiência como sem deficiência, de modo a estruturar suas demandas particulares.

Uma das ferramentas mais importantes para o desenvolvimento do projeto foi a setorização sistemática baseada em suas matrizes de funções e espacialidades. Visto que, após a definição dos sete grupos funcionais, foi possível traçar as diferentes correntes ideológicas para adoção do partido final, discutidas nos métodos de aplicação, baseadas no wayfinding. Assim, gerando a definição e adoção das cores como ferramenta para integração entre os modelos sistemáticos, permeando a sinalização de piso e parede. 




$\mathrm{Na}$ busca por soluções cada vez mais integrais e acessíveis, a união de diferentes texturas e aplicação dos elementos de sinalização coloridos - faixas - em planos verticais pode se apresentar como possíveis intervenções igualmente ricas e inclusivas. Tendo sido essa uma solução estudada e pensada, porém destacada pela grande quantidade de mudanças de fluxo presentes na edificação, o que ajudaria a reduzir a perceptividade deste sistema. Porém, em objetos de estudo com menor complexidade espacial/funcional, ou com maior continuidade nas paredes poderia ser uma prática aplicada e que viabilizaria a união de informação visual e tátil.

Por fim conclui-se que ao focar na informação visual o uso das cores se destaca fortemente como uma importante ferramenta a ser trabalhada. Ela possibilita variedade em sua aplicação, uma vez que responde a diferentes escalas do partido arquitetônico e sua complexidade. Na reitoria acabou por ser vinculada exclusivamente ao piso - através das faixas - e paredes, através das placas. Entretanto, buscando relações coma identidade visual ela poderia também apresentar uma setorização por pavimentos, distribuindo a estes diferentes pontos da escala cromática adotada. Porém, a adoção utilizada também se mostra eficaz- evidenciando que cada caso é um caso - podendo não apenas identificar ambientes, como também, permear todos os diferentes sistemas e integrá-los discretamente.

\section{REFERÊNCIAS}

ASSOCIAÇÃO BRASILEIRA DE NORMAS TÉCNICAS (ABNT). NBR 9050: Acessibilidade a edificações, mobiliário, espaços e equipamentos urbanos. Rio de Janeiro: ABNT, 2015.

AZEVEDO, M. F. M.; SANTOS, M. S.; OLIVEIRA, R. Oliveira, Rúbia de. O uso da cor no ambiente de trabalho: uma ergonomia da percepção. Ensaios de Ergonomia: Revista Virtual de Ergonomia. Florianópolis: UFSC, jun.2000

BRASIL. Decreto-lei no. 5.296. Regulamenta as Leis no 10.048, de 8 de novembro de 2000 , que dá prioridade de atendimento às pessoas que especifica, e no 10.098 , de 19 de dezembro de 2000, que estabelece normas gerais e critérios básicos para a promoção da acessibilidade das pessoas portadoras de deficiência ou com mobilidade reduzida, e dá outras providências. Brasília, 2004.

BRASIL. Lei no 13.146. Institui a Lei Brasileira de Inclusão da Pessoa com Deficiência (Estatuto da Pessoa com Deficiência). Brasília, 2015.

DISCHINGER, M.; MATTOS, M. L.; BRANDÃO, M. M.; BINS ELY, V. H. M. Orientar-se em campi universitários no Brasil: condição essencial para a inclusão. Ponto de Vista, Florianópolis, n. 10, p. 39-64, 2008.

DUARTE, C. R. S.; COHEN, R. Acessibilidade aos Espaços do Ensino e Pesquisa: Desenho Universal na UfRJ - Possível ou Utópico? In: NUTAU: Demandas Sociais, Inovações Tecnológicas e a Cidade, 2004, São Paulo.

IIDA, I. Ergonomia: projeto e produção. Ed. Edgard Blucher Ltda. São Paulo. 3a Edição. 2006.

SIMÕES, P. "Se Deus te assinalou algum defeito te encontrou" o design e contributos para a sinalética urbana. In: Congresso Internacional Cidades Criativas. 5, 2017. Cidade do Porto. Anais... Cidade do Porto, 2017. 